\title{
Benthic diving in male emperor penguins Aptenodytes forsteri foraging in winter
}

\author{
D. Rodary ${ }^{1,2, *}$, W. Bonneau ${ }^{1}$, Y. Le Maho ${ }^{1}$, C. A. Bost ${ }^{1}$ \\ ${ }^{1}$ Centre d'Écologie et Physiologie Énergétiques, 23 rue Becquerel, 67087 Strasbourg, France \\ ${ }^{2}$ Université du Québec à Rimouski, 300 allée des Ursulines, G5L 3A1 Rimouski, Québec, Canada
}

\begin{abstract}
We studied the foraging areas and diving depths of male emperor penguins Aptenodytes forsteri raising chicks at Pointe Géologie, Adélie Land, in relation to bathymetry and sea-ice conditions during the first foraging trip after incubation in August 1996 and 1997. Combining satellite-tracking and dive-recording devices on the same penguins allowed individual dives to be localised and related to water depth. The penguins mostly dived in zones less than $300 \mathrm{~m}$ deep, where they performed $50 \%$ of their dives and spent $54 \%$ of their bottom time near the sea floor, on average. Analyses including bathymetry and sea-ice cover for the 2 years suggest that after leaving the colony the penguins targeted the nearest available, fast-ice free shallow shelf waters $(<300 \mathrm{~m})$. Once in these areas, the penguins foraged by diving near the sea floor during most of the remaining part of their foraging trip. Day-by-day analysis showed that during this central part of the foraging trip, $68 \%$ of the dives ended near the sea floor. The most likely function of these dives appeared to be feeding on benthic or bentho-pelagic prey. Benthic dives were rare during the first and last days of trips, when penguins were apparently in transit. Benthic-feeding is interpreted as a strategy towards predictable prey during a critical stage of the breeding cycle. Shallow areas of the Antarctic continental shelf may be important for some emperor penguin colonies around Antarctica. The importance of the benthic strata for this top predator of the Antarctic shelf ecosystem gives new insights on the trophic networks in the pack-ice during the Antarctic winter.
\end{abstract}

KEY WORDS: Benthic dives $\cdot$ Emperor penguins $\cdot$ Foraging behaviour $\cdot$ Satellite tracking $\cdot$ Dive recording

Resale or republication not permitted without written consent of the publisher

\section{INTRODUCTION}

The emperor penguin Aptenodytes forsteri dives deeper than any other seabird, with a maximum recorded dive to $534 \mathrm{~m}$ (Kooyman \& Kooyman 1995). In winter, these birds seem to forage mostly over the continental shelf, in areas where the sea floor is usually not deeper than 200 to $400 \mathrm{~m}$ and thus within reach of the penguins (Robertson 1994, Wienecke \& Robertson 1997). The benthic zone of the Antarctic shelf sustains a high biomass of fauna (Brey \& Clark 1993, Brey \& Gerdes 1997), including large numbers of benthic and bentho-pelagic fishes which depend on other benthic organisms as a primary food source (Koch 1992). Since

*E-mail: danrodary@ifrance.com the diet of emperor penguins frequently includes some of these species (Piatkowski \& Pütz 1994, Robertson et al. 1994), these birds may use their extraordinary diving abilities to dive to the sea floor.

Despite the evidence of benthic dives (i.e. to or near the sea floor), the only way to study foraging behaviour in relation to bathymetry is to simultaneously record the penguin's position and diving activity at sea (see Wilson et al. 1994). Such studies have already been conducted on emperor penguins, but they focused mainly on the relationship between foraging locations and sea-ice conditions, and involved only a few individuals, with most of the records being incomplete (Ancel et al. 1992, Kirkwood \& Robertson 1997a). These studies, however, mentioned that some of the deepest dives performed may have reached the sea-floor. The 
most recent and extensive study combining satellitetracking and dive recording linked the dives performed each day to the depth at the penguin's position at noon (Wienecke \& Robertson 1997). The authors suggested that the diving behaviour of the penguins might have been influenced by the water depth.

In the present study we aim to evaluate the influence of bathymetry on the foraging behaviour of emperor penguins. To do this we attempted to relate dive and water depth on an individual-dive basis, which necessitated calculating each dive's location and the depth of the water at this location. Since deep dives seem to occur mostly in winter (Kirkwood \& Robertson 1997b) and are mostly performed by males (Wienecke \& Robertson 1997), we focused this study on males foraging in winter. Our first goal was to demonstrate the existence of benthic diving and to quantify the frequency of these dives in male emperor penguins during winter. In a second part, we evaluated the influence of this diving behaviour on the foraging strategy. Finally we analysed this strategy in regard to constraints such as ice cover and breeding cycle.

\section{MATERIALS AND METHODS}

Study colony, selected penguins and instrument characteristics. The study was conducted at the Pointe Géologie emperor penguin colony $\left(66^{\circ} 40^{\prime} \mathrm{S}, 140^{\circ} 01^{\prime} \mathrm{E}\right)$, near Dumont D'Urville (DDU) station, in August 1996 and August 1997. At this stage of the breeding cycle (in early August), the chicks are 1 to $10 \mathrm{~d}$ old. After the return of the females from their winter foraging trip, the males go at sea for about $20 \mathrm{~d}$ before returning to feed the chicks (Robertson 1994). Therefore, we assumed that penguins leaving the colony just after the peak of female arrivals were breeding males going to sea for their first foraging trip after their 4 mo incubation fast.

We used time-depth recorders (TDRs) to record the dives and platform transmitter terminals (PTT) to track the penguins during their foraging trips. The TDRs (model MK6, $3 \mathrm{~m}$ depth resolution, 0 to $750 \mathrm{~m}$ depth range, Wildlife Computers, USA) weighed $120 \mathrm{~g}$ and had a frontal area of $15 \mathrm{~cm}^{2}$, or about $2.5 \%$ of a $24 \mathrm{~kg}$ penguin's cross-sectional area (Wienecke \& Robertson 1997). The memory could store $512 \mathrm{kB}$ of data and the sampling interval for depth was set at $10 \mathrm{~s}$. This sampling interval was chosen to obtain complete and continuous records of the foraging trips while allowing relatively accurate dive profiles (see Boyd 1993, Wilson et al. 1995). The PTT (model ST-10, Telonics, USA, modified by Sirtrack, New Zealand, to include a VHF transmitter) weighed $260 \mathrm{~g}$ and had a frontal area of $15 \mathrm{~cm}^{2}$ and a $17.5 \mathrm{~cm}$ antenna. It transmitted at
$90 \mathrm{~s}$ intervals on a $15 \mathrm{~h}$ on $/ 9 \mathrm{~h}$ off cycle, transmitting between 14:00 and 05:00 h local solar time, because penguins were considered easier to locate when they were out of the water at night (Kirkwood \& Robertson 1997a). The short-range VHFs transmitted at 40 pulses $\mathrm{min}^{-1}$ and allowed us to locate approaching penguins in any weather and at night.

The penguins were caught on their way to the sea, more than $1 \mathrm{~km}$ away from the colony. They were fitted with both instruments which were glued (Loctite $401^{\mathrm{TM}}$ ) to the feathers on the midline of the lower back to minimise drag (Bannasch et al. 1994). When they returned to the colony to attend their chicks, the penguins were recaptured before reaching the colony, and their instruments removed.

Studied penguins. Four male emperor penguins were fitted with the instruments in 1996, and 6 in 1997. In 1996, 1 penguin was not recaptured and was consequently not included in the analysis because we could not analyse the dive record of this bird. Another penguin was excluded in 1997 because it returned to the colony after $48 \mathrm{~d}$ at sea, while the second longest trip of our penguins was $22 \mathrm{~d}$. Although it was seen feeding a chick after returning, its breeding probably failed, as it is very unlikely that the female could have maintained its newly hatched chick alive for such a long period. We think that this penguin was seen feeding an adopted chick (see Jouventin et al. 1995). Unlike the others, it made a long trip to the north and foraged in the oceanic area more than $440 \mathrm{~km}$ away from the colony, where water depth was consistently over $2000 \mathrm{~m}$, while the others remained within $122 \mathrm{~km}$ of the colony. This bird is thought to be a young breeder (see Wienecke \& Robertson 1997 on 2 females that went more than $500 \mathrm{~km}$ away while the 10 others stayed within $180 \mathrm{~km}$ of the colony). This penguin was thus excluded because it seemed to represent an exception to the observed breeding adult's behaviour, and was probably not a breeder, at least after this trip. We nevertheless analysed its diving behaviour, and found similarities with other males when it foraged over the continental shelf (Appendix 1). We thus analysed 8 foraging trips over the 2 years in this study.

Evaluation of the accuracy of satellite tracking and selection of the fixes. Before each use, the PTTs were deployed for a few days at DDU in order to get fixes (position of the PTTs as calculated by the satellite) from a known position. We also used the fixes calculated for penguins that could not be caught on their return and that spent a few days at the colony attending their chicks before being captured on their next departure. We could then determine the proportion of fixes that lay within a given distance of the known true position at our latitude and at the time of the study (1996 to 1997). We recorded 1694 fixes from 
known positions during the 2 years. The Argos tracking system provides a ranking system for the quality of location estimates ('LQ') which, in order of descending accuracy, is 3, 2, 1, 0, A and B (Argos User Manual 1988). We compared the accuracies we recorded with those predicted by Argos for each class of accuracy (DDU/Argos Ratio, Table 1). Observed accuracy was lower than Argos predictions for Classes 3 and 2, but only slightly lower for Class 1 (see ratios in Table 1). Quality classes for which Argos does not give any predictions of accuracy ( $0, \mathrm{~A}$ and $\mathrm{B})$ were found to be less reliable than Class 1 by a factor of more than 2 . Considering this difference in accuracy between Class 1 and lower classes, and also considering that at the $90 \%$ threshold the distance from the true position extended to more than $17 \mathrm{~km}$ for classes under Class 1, we included only fixes of Classes 3, 2 and 1 in our study, as did Hull et al. (1997) after a similar calibration. These fixes were further filtered by manually eliminating the unlikely positions when speed between 2 locations exceeded $15 \mathrm{~km} \mathrm{~h}^{-1}$, which is thought to be the maximum sustainable speed for emperor penguins (Wienecke \& Robertson 1997).

Location of individual dives. We assumed that the selected locations were representative of the penguin's path, which implies that the penguins moved at a constant speed on a straight line between each location (mean distance between locations: $3.1 \pm 0.5 \mathrm{~km}$ ). Based on this assumption, each dive was located by linear interpolation between the 2 closest satellite-determined locations.

Dive analysis. The data collected by the TDRs were first analysed with custom software (Jensen Software Systems, Laboe, Germany) to correct for drift in the baseline (zero offset correction). All dives $>10 \mathrm{~m}$ were included, and the only parameters considered for the present study were the maximal depth of each dive and the time spent at or near the maximum depth (bottom time). Bottom time was defined as the flat part of the dive profile near the maximum depth, the thresh- old for beginning (or end) of the bottom being a vertical speed lower (or higher) than $0.2 \mathrm{~m} \mathrm{~s}^{-1}$ (see Rodary et al. 2000).

Calculation of the sea floor depth at given locations. To calculate the depth at each location, we used the ETOPO5 5 minute gridded elevation database (National Geographic Data Center 1988). This database indicates the altitude (or depth) of the Earth's surface at $5^{\prime}$ intervals, which represents a $3.6 \mathrm{~km}$ interval from west to east, and $9.2 \mathrm{~km}$ from north to south at $66^{\circ} \mathrm{S}$. This $5^{\prime} \times 5^{\prime}$ grid was analysed with Geographic Information System software (Arc/Info ${ }^{\mathrm{TM}}$, ESRI Canada Ltd, Toronto, Canada) to calculate a continuous surface with a spline interpolation function, which ensures that the resulting surface includes all the points of the grid and minimises curvature between points. We assumed that this surface represents the sea floor, and could then calculate the depth of the sea floor for any given position.

Ice characteristics. We used satellite infrared images of the sea-ice to define the different types of ice covers analysed in this study (resolution $1 \mathrm{~km}$, Arctic \& Antarctic Research Center, Scripps Institution of Oceanography, La Jolla, CA, USA). On these images the coldest surfaces (continental ice) appear white, while the warmest (open ocean) appear black. Different concentrations of ice plates on the water are translated into various tones of grey. In our study, fast-ice was defined as the plate of thick sea-ice (the coldest surface at sea) which is attached to the coast and probably to grounded icebergs offshore, and which was present and mostly unchanged on satellite images over the month of the study. All the rest of the area offshore was defined as pack-ice because it showed extensive changes from day to day on satellite images, and because it did not seem to prevent access to the water by the penguins. In 1996 there was an area enclosed between the coast and the fast-ice plate offshore that seemed to have a higher surface temperature than fast-ice on satellite images (i.e. to be thinner and/or more open), but where

Table 1. Aptenodytes forsteri. Accuracy of location fixes at Dumont D'Urville (DDU, $\left.66.67^{\circ} \mathrm{S}\right)$ compared to the accuracy predicted by Argos (Argos User Manual 1988), for quality classes ranging from 3 (best) to B (poorest). The DDU/Argos ratio indicates the discrepancy between our observations and predictions of Argos Systems. For additional information the distances including $90 \%$ of the fixes are also indicated

\begin{tabular}{|c|c|c|c|c|c|}
\hline \multirow{2}{*}{$\begin{array}{l}\text { Location } \\
\text { quality } \\
\text { (LQ) }\end{array}$} & \multirow[t]{2}{*}{$\mathrm{N}$} & \multicolumn{2}{|c|}{$\begin{array}{l}\text { Distance from the true position within } \\
\text { which } 68 \% \text { of locations lay (m) }\end{array}$} & \multirow[t]{2}{*}{$\begin{array}{l}\text { DDU/Argos } \\
\text { ratio }\end{array}$} & \multirow[t]{2}{*}{$\begin{array}{c}\text { Distance from the true position within } \\
\text { which } 90 \% \text { of locations lay }(\mathrm{m})\end{array}$} \\
\hline & & DDU & Argos predictions & & \\
\hline 3 & 203 & 691 & 150 & 4.6 & 1153 \\
\hline 2 & 309 & 930 & 350 & 2.7 & 1781 \\
\hline 1 & 493 & 1436 & 1000 & 1.4 & 5275 \\
\hline 0 & 195 & 5687 & $>1000$ & & 59570 \\
\hline $\mathrm{A}$ & 253 & 3330 & - & & 17728 \\
\hline B & 241 & 16904 & - & & 62533 \\
\hline
\end{tabular}


penguins could apparently walk. Personal observation in the winter pack-ice led us to conclude that it was probably thin and almost continuous fast-ice with frequent pools of water (D.R. pers. obs.). We consequently classified this area as thin fast-ice in Fig. 4.

Statistics. To estimate the proportion of benthic dives for 8 penguins diving in areas of various depths, one needs to define benthic dives independently of sea floor depth. Defining benthic dives as those ending $20 \mathrm{~m}$ or less above the sea floor, for example, would not allow detecting a preference for this benthic layer, because the thickness of the non-benthic layer (i.e. the distance between the surface and the $20 \mathrm{~m}$ thick 'benthic layer') would vary between penguins or between foraging days. To solve this problem we determined the relative depth of each dive, defined as the ratio between dive and water depth at this location (e.g. a dive to $180 \mathrm{~m}$ in waters $200 \mathrm{~m}$ deep would reach the $90 \%$ class of relative depth). We calculated the distribution of dives in $10 \%$ classes of relative depth for each bird. This process was also applied to the bottom time, by calculating the proportion of total bottom time per class of relative depth. Individual values in each class were used as the sampling unit to avoid pseudoreplication (see Aebischer et al. 1993), thus producing 8 compositions of 10 proportions describing the proportional use of each depth class by the 8 penguins. Conventional analysis (ANOVA) was not possible because (1) the values across the 10 classes were from the same individuals and (2) for each individual, the sum of the 10 classes was $100 \%$. These 2 constraints prohibited the use of any methods requiring the independence of data. The small number of individuals, and the fact that we had more groups than individuals also prevented the use of alternative methods such as compositional analysis (Aebischer et al. 1993).

We thus used a randomisation test elaborated from the data itself to test whether the mean distribution observed was significantly different from what random use of the depth classes by each penguin could produce (see Manly 1991). The basis of this approach was that if penguins dived at random depths, then the mean proportion of dives per depth class should tend to 0.1 , assuming that they had equal access to each of the 10 classes (possible results of a violation of this assumption are discussed).

We thus simulated $\mathrm{N}$ groups of 8 penguins with random distribution of their dives across the 10 depth classes, calculated their mean proportion of dives per class for the 8 penguins and measured the deviation from random use for each class, that is the difference between the calculated mean and the expected value of 0.1 (see Appendix 2). These deviations from random use (DRUs) were then compared to the DRUs calculated for the reference group of 8 penguins (i.e. the real penguins). Over the $\mathrm{N}$ simulations, each occurrence of a simulated DRU being equal to or higher than the observed DRU of the corresponding class was recorded. After $\mathrm{N}$ simulations, if in a given class there had been $\mathrm{n}$ occurrences of this event (simulated DRU $\geq$ observed DRU), then the frequency of occurrence was $\mathrm{f}=\mathrm{n} / \mathrm{N}$ and this event could be said to have a probability of $\mathrm{p}=\mathrm{n} / \mathrm{N}$ of occurring at random. If $\mathrm{p}$ was small, for example under 0.05 , then the hypothesis of the observed DRU occurring by chance could be rejected at the level $\alpha=0.05$. Signs of the DRUs were taken in account, to produce a 1-tailed probability.

To achieve good precision of the results and minimise the chances of creating a particular distribution of the simulated DRUs, $\mathrm{N}$ had to be fairly large, and we thus ran 2500 simulations. This theoretically allows detecting events with a probability of occurrence as low as $p=1 / 2500=0.0004$, and reduces to almost nothing the chances of producing a particular (non-random) set of simulated groups.

\section{RESULTS}

\section{Relationship between diving depth and water depth during the foraging trip}

For each bird we plotted the dive depth and the sea floor depth calculated for each dive, over the whole foraging trip, against time (Fig. 1). Fig. 1 shows how the dives were concentrated near the sea floor between 150 and $200 \mathrm{~m}$, indicating high proportions of benthic dives, and contrasting with the restricted use of the remaining part of the water column.

\section{Proportion of benthic dives and proportion of bottom time per depth class}

For the 8 penguins, $32 \%$ of all dives were to depths between 90 and $100 \%$ of the water depth (Fig. 2). The 2 deepest classes of relative depth (between 80 and $100 \%$ of water depth) included $50 \%$ of all the dives, while no other class contained more than $10 \%$. Such a simultaneous departure from random use in the 2 deepest classes of relative depth had a probability of $\mathrm{p}<0.001$ to occur at random (see Appendix 2). The hypothesis of random use of each depth class by penguins could thus be rejected at the $\alpha=0.001$ level, with the alternative hypothesis being that the 2 deepest classes were used significantly more often than by chance and thus preferred.

The same analysis was applied to the proportion of bottom time per depth class, and there again the null hypothesis of random distribution of the bottom time 

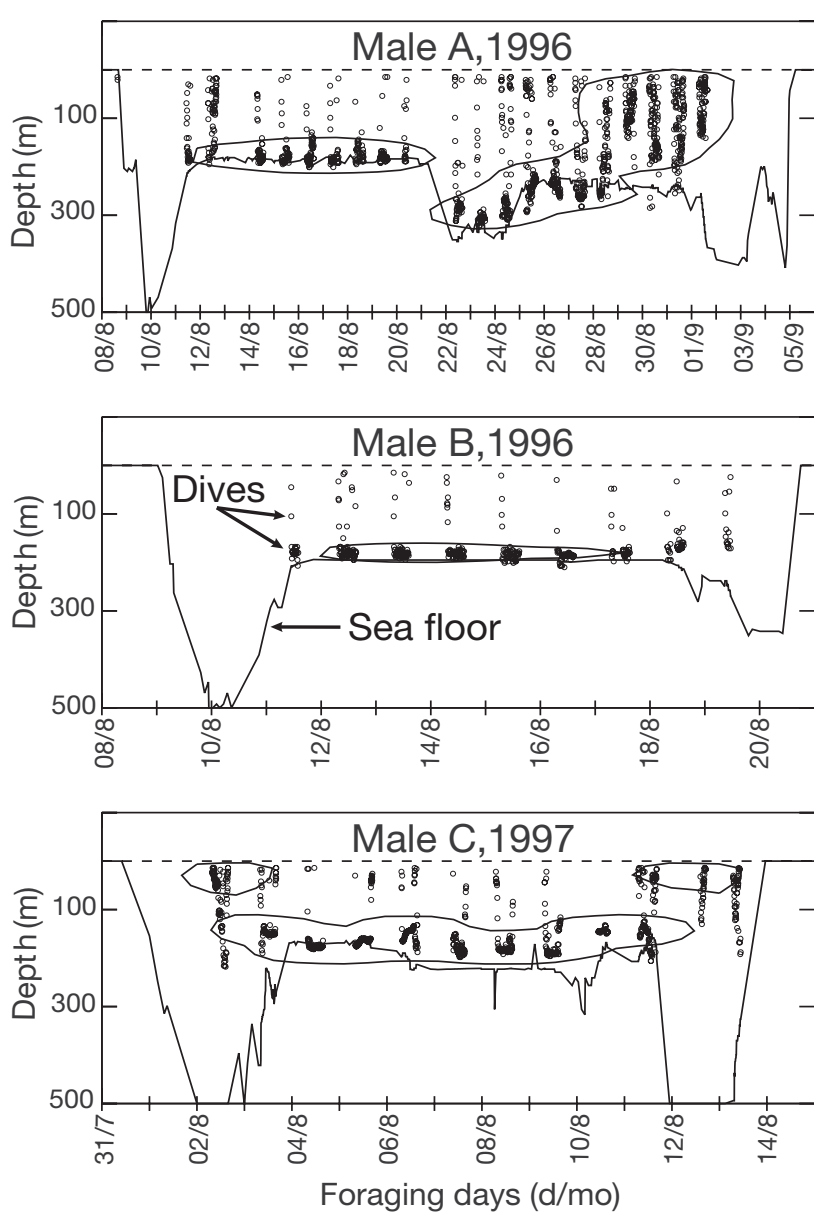

Fig. 1. Dive depths of 3 male emperor penguins (o), in relation to the sea floor depth calculated for each dive (continuous line). Each circle represents the maximum depth of 1 dive. The broken line indicates the surface. To visualise the concentrations of dives we calculated $75 \%$ kernel density contours (enclosed areas). Note that the $x$-axis is time, and that the sea floor only indicates depth where the penguins spent time and dived (for example, Male B stayed in the same area between $12 / 8$ and 18/8, rather than traveling over a flat area for this period)

could be rejected, at the $\alpha=0.0005$ level, with the alternative hypothesis being that the 2 deepest classes were used significantly more often than by chance and thus preferred.

The average proportion of benthic dives calculated over complete foraging trips (50\% of the dives) was exceeded during what appeared to be a 'central part' of the trips. The daily mean proportion of benthic dives rose over $50 \% 2 \mathrm{~d}$ after departure from the colony and dropped under $50 \%$ for the last $3 \mathrm{~d}$ of foraging. The 'central part' of the foraging trip could then be defined, in terms of benthic diving, as the foraging trip without the first 2 and the last $3 \mathrm{~d}$. During this central part, the mean proportion of benthic dives rose to $68 \%$ for all penguins.

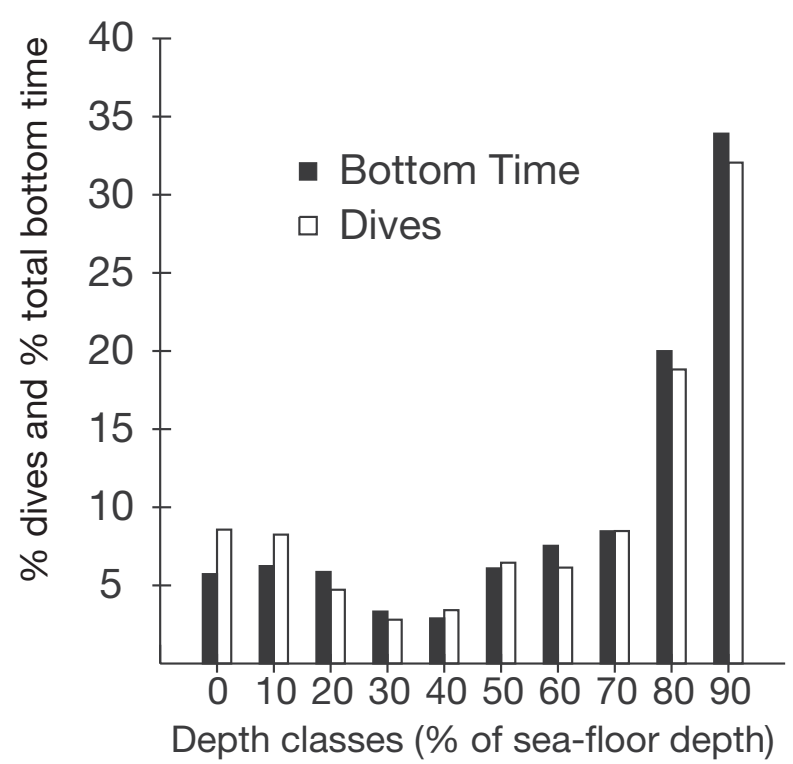

Fig. 2. Mean percentages of dives and total bottom time per relative depth class for the 8 penguins. Lower values of each class are indicated

\section{Bathymetry off Adélie Land coasts and diving locations of penguins}

The map drawn from the ETOPO5 database (Fig. 3) indicates that all types of topography were present within the mean maximum range of the penguins in both years (60 and $90 \mathrm{~km}$ arcs). This is due to the deep valley $(>700 \mathrm{~m})$ that cuts into the continental shelf to the north-west of DDU and almost reaches the coast north of DDU. To determine the availability of foraging grounds to the penguins, however, fast-ice must be taken into account (Fig. 4a,b).

In 1996, the emperor penguins dived mostly in packice east of the fast-ice edge, where the water depth ranged from 200 to $300 \mathrm{~m}$ (Fig. 4a, Box B). To reach this area they travelled eastward across an area where ice conditions were not clearly established ('thin fast-ice'; see 'Material and methods' and Fig. 4a). The penguins crossed this area without diving, except in a small area along the fast-ice plate (Box A). They all dived there before reaching heavier fast-ice and crossing it without diving. One penguin (Male B in Fig. 1) actually dived only in this area during its $12 \mathrm{~d}$ foraging trip. The water there was also between 200 and 300 m deep.

In 1997, the penguins headed north and crossed less than $20 \mathrm{~km}$ of fast-ice, without diving, before reaching pack-ice (Fig. 4b). They then travelled to the northeast in the pack-ice, diving frequently over an area where the water depth ranged from 300 to $700 \mathrm{~m}$ (e.g. Male C foraging between 02/8 and 04/8, Fig. 1). They reached the western side of the fast-ice plate, but they did not cross it. Instead, they concentrated all their 


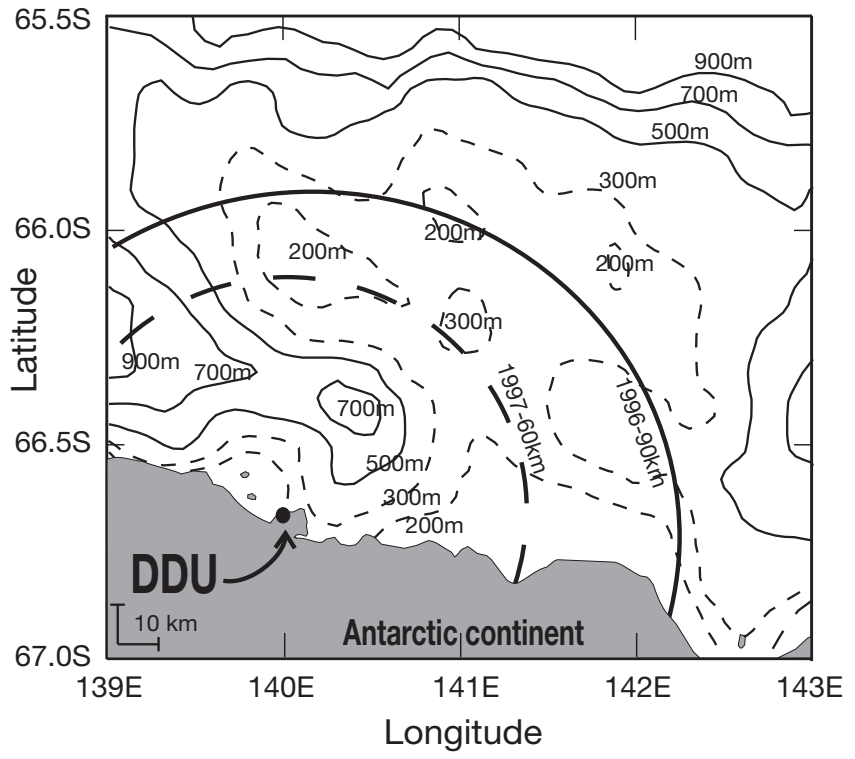

Fig. 3. Sea floor topography off Adélie Land, Antarctica, as calculated from ETOPO5 elevation database (see 'Materials and methods'). The mean individual maximal distances from colony for each year are indicated with continuous and broken $\operatorname{arcs}$ (90 km in 1996 and $60 \mathrm{~km}$ in 1997, respectively)

dives in an area bound by the fast-ice on the east and by the $300 \mathrm{~m}$ isobath on the south, thus diving in water from 180 to $300 \mathrm{~m}$ deep (Area A in Fig. 4b)

\section{DISCUSSION}

\section{Diving behaviour and accuracy of the methods}

This study provides the first evidence that male emperor penguins from DDU may dive mostly to the vicinity of the sea floor during their winter trip. More than half of all dives recorded were deeper than $80 \%$ of the water depth, one-third reached $90 \%$ or more of the water depth, and the distribution of bottom time also reflected this trend towards the 2 deepest classes of relative depth (Fig. 2). The initial assumption of our statistical approach, that the penguins had equal access to all classes of relative depth, can be violated in the case of dives performed over very deep waters exceeding the maximum diving capacity of emperor penguins (i.e. more than $500 \mathrm{~m}$ ). But if this was the case for some dives, it will have biased the distribution towards a higher proportion of dives (and bottom time) in the first classes (i.e. 0, 10, 20\%) and lower proportions in the deepest classes. The result of our tests would then have been weakened, and the significance of the tests with the present values can thus be considered a conservative result, which could only have been more marked without this potential bias.

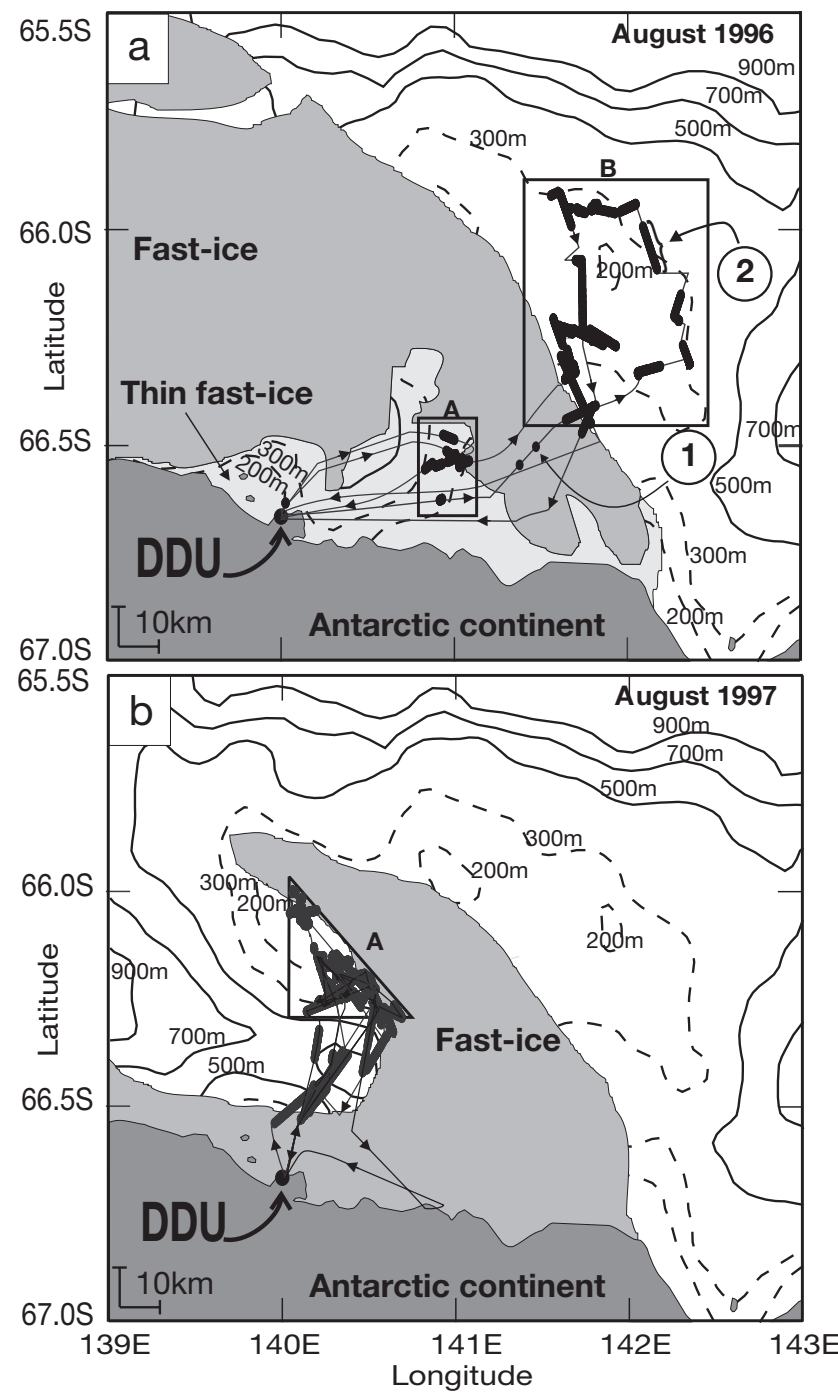

Fig. 4. Sea floor topography, ice cover and penguin diving locations off Adélie Land, Antarctica, in August 1996 (3 penguins) and 1997 (5 penguins). For clarity, pack-ice is not represented, as it covered the whole area free of fast-ice for both years. Arrows indicate examples of: (1) isolated dives, (2) a series of consecutive dives. Tracks were slightly smoothed for the presentation, without altering dive locations. Arrowheads on the tracks indicate the direction of travel

There are many imprecision factors in this study, arising from both calculated parameters, the estimation of sea floor depth and the approximation of the dives locations. The sea floor surface was interpolated from a $5^{\prime} \times 5^{\prime}$ grid, obtained from another minimumcurvature algorithm applied to a larger-scale grid in areas where data are scarce (National Geographic Data Center 1988). We therefore smoothed the topography of the real sea floor with these calculations. The calculation of dive locations raised the same problem, namely that accurate locations were scarce and mostly obtained at night. The linear interpolation between 
consecutive fixes thus often reduced $1 \mathrm{~d}$ of foraging to a line between the morning and the evening location of the penguin. This undoubtedly oversimplifies a penguin's track during the day.

These uncertainties resulted in an occasional inaccurate representation of reality, as the penguins appeared to dive deeper than the calculated sea floor. Overall, 1342 dives out of 7293 (18.5\%) were under the calculated sea floor, but these dives 'under the sea floor' were very close to it: $14 \%$ were less than $20 \mathrm{~m}$ under the sea floor, and another $4 \%$ exceeded the sea floor depth by 20 to $40 \mathrm{~m}$. Hence, $99.5 \%$ of all dives were either above the sea floor or 0 to $40 \mathrm{~m}$ deeper. No dive exceeded the sea floor depth by more than $80 \mathrm{~m}$. We thus think that, overall, our calculation methods reflected reality.

\section{Foraging strategy}

Assuming that the calculated depths correctly represent the sea floor, one may wonder whether benthic diving was not merely a result of local bathymetry, i.e. if penguins were not restricted in their diving behaviour by limited access to deeper waters. The bathymetry off Adélie Land (Fig. 3) shows that the penguins covered distances enabling them to reach any water depths from 0 to $900 \mathrm{~m}$ or more. Even though fast-ice reduced greatly the area available to the penguins, varying water depths still occurred within the penguins' foraging ranges (Fig. 4a,b). Thus, the penguins were not restricted to shallow water by local bathymetric features or by the sea-ice conditions.

Overall, penguins dived mostly in areas with common characteristics: they were shallower than $300 \mathrm{~m}$, fast-ice free and were the closest zones with these characteristics to the Pointe Géologie colony, but not the closest fast-ice free areas (Fig. 4a,b). In 1996, the closest access to light pack-ice was either due north or to the north-east of DDU. Two penguins entered the water at the north-east access, where waters were around $350 \mathrm{~m}$ deep, but both moved north and east to waters $<300 \mathrm{~m}$. In 1997, the closest access to light pack-ice was due north of DDU, in waters between 300 and 700 m deep. All penguins reached the water there, and all immediately moved north and slightly east, thus choosing the shortest way to the closest area $<300 \mathrm{~m}$. We consequently propose that diving locations reflected a foraging strategy orientated towards benthic diving in shallow areas, the penguins apparently making the best of the bathymetric features in conjunction with fast-ice cover to forage in these shallow areas while minimising distance to the colony.

Although benthic diving was clearly a major component of the foraging strategy, the penguins spent some of their days at sea foraging with almost no benthic dives, and this occurred mostly during the first and last days of diving (see Males A and C in Fig. 1). These non-benthic dives were rare during the central part of the trips, which showed higher proportions of benthic diving (68\% on average). During foraging trips, diving started and ended at the nearest access to the water from the colony, which was determined by ice conditions and probably not chosen by penguins. We thus suggest that the penguins had to travel over these areas in transit to and from their preferred foraging zone, and that interpretation of the diving behaviour during the trips must take into account breeding constraints forcing the penguins to transit between their colony and their foraging grounds. Considering these constraints, one interpretation may be that the penguins actively searched for suitable foraging areas for benthic diving, although they opportunistically began to dive before reaching these areas and kept on diving after leaving them to return to the colony.

\section{Influence of bathymetry and sea-ice conditions on foraging behaviour}

The importance of benthic diving during this period of the breeding cycle may be greater than expected from previous studies based on remote monitoring (i.e. dive recording and satellite tracking) or diet analysis (Ancel et al. 1992, Robertson 1994, Kooyman \& Kooyman 1995, Kirkwood \& Robertson 1997a, Wienecke \& Robertson 1997). If benthic diving is of similar importance in other areas, it could have been underestimated by previous remote monitoring studies because of the small number of birds studied during this period of the emperor's cycle and particularly because of the scarcity of bathymetric data for theses areas of the earth. For diet studies, the difference in diving behaviour that we detected between the central and last days of the foraging trips confirms that analysis of the diet from stomach samples of returning penguins might be misleading (Kooyman \& Kooyman 1995). It may overestimate the importance of midwater prey captured during the last days, which may furthermore be preserved from digestion for delivery to the chick as it has been observed in other penguin species (Wilson et al. 1989, Pütz \& Bost 1994, Peters 1997).

The high proportion of benthic dives observed enables us to discuss the supposed function of these dives from a new point of view. The need to gather gastric stones (Kooyman \& Kooyman 1995) cannot be invoked for more than a few dives. Similarly, dives for navigational purposes (Kirkwood \& Robertson 1997a) may not constitute a significant part of the benthic dives recor- 
ded in our study. The third supposed function of the deep dives, feeding on benthic prey (Robertson 1994, Kirkwood \& Robertson 1997a), consequently stands as the most likely explanation for these benthic dives. Deep diving could be energetically worthwhile if it allows the penguins to catch large-bodied prey such as squid or bentho-pelagic fishes (Costa 1991, Kirkwood \& Robertson 1997a). We suspect that it could also be profitable in terms of higher predictability of resources from one year to another. Predictability of resources is an important factor for the other species of the Aptenodytes genus, the king penguin Aptenodytes patagonicus, which travels far from its colony to reach the rich waters of the Antarctic Polar Front (Bost et al. 1997). Foraging at known locations, where densities of prey may be more predictable over time, might be particularly interesting for male emperor penguins during the first foraging trip after their incubation fast. At this stage of the cycle they have to restore their own fat reserves and gather food for their chicks. The importance of this constraint is thought to cause the unbalanced sex ratio among emperor penguins, the survival rate of males during this critical period lowering their yearly survival rate in comparison with females (Jouventin et al. 1984). A trip duration of 10 to $20 \mathrm{~d}$ does not leave many days for exploration of the highly variable pelagic environment. When the males reach the sea in August, almost all parameters of the marine environment (e.g. ice cover, light levels, primary production) are likely to have changed since their last foraging trips in May, except for the topography of the sea floor. This permanence of the topography is reflected in the abundance and distribution of Antarctic benthic and bentho-pelagic fishes: being mostly dependent on the seasonally stable and abundant benthic fauna (Koch 1992, Brey \& Clark 1993), and being mostly long-lived and slowly growing species (Koch 1992), they tend to show greater small-scale predictability than pelagic species throughout the seasons and years (J. C. Hureau pers. comm.). We consequently suggest that by performing benthic dives at known locations with predictable abundance of prey, male emperor penguins optimise their time at sea during the constraining period of the first foraging trip.

If male emperor penguins from DDU rely on specific and known shallow areas of the continental shelf to forage in winter, the influence of sea-ice would then be of greater importance than assumed up to now. The current hypothesis is that fast-ice imposes a temporal and energetic cost through the delays occasioned in foraging trips when birds have to spend days commuting between the colony and the ice edge (Wienecke \& Robertson 1997). If the fast-ice extended only slightly more to the east than in winter 1996, all shallow areas near DDU would be covered and not available to the penguins (see Fig. 4a). This second possible effect of the fast-ice is likely to have more drastic consequences on the penguins, as they would then not only have to walk 1 or 2 more days to reach the water, but also to change their foraging behaviour once at sea and hunt for pelagic prey, which may be less predictable in abundance and distribution. This, in addition to large-scale changes in resource distribution and abundance, could cause a significant increase in the time needed to restore their own fat reserves, which would then delay their return to the colony and could account for the massive chick-rearing failures that were observed in certain years with extended fast-ice cover (C.A.B. unpubl. data).

Comparisons with other studies suggest that benthic diving in shallow areas may occur at other locations and at other stages of the breeding cycle. Kirkwood \& Robertson (1997a) observed that in 1988 the Mawson Coast's continental shelf was relatively ice-free, and the diet of emperor penguins comprised mainly squid and shelf-dwelling species and was relatively stable throughout the breeding season (Robertson 1994). In comparison, in 1993, the shelf was first covered by fast-ice and then opened in early summer, causing the emperors to increase their dietary intake of shelfdwelling fishes, probably after a move towards the newly opened areas.

In conclusion, shallow areas of the continental shelf are likely to be important foraging areas for emperor penguins at some localities in winter, and perhaps also during other periods of the breeding cycle. Future studies may extend and test this hypothesis over the whole breeding cycle and at other foraging locations, which could lead to defining high-sensitivity areas for emperor penguins in the prospect of commercial fishing taking place in the coastal waters of Antarctica in the near future. The importance of the benthic stratum in the Antarctic continental shelf food webs may also need reconsideration, as we show that one of the top predators in this area seems to rely on this stratum during a critical phase of its breeding cycle.

Acknowledgements. The Institut Français pour la Recherche et la Technologie Polaire (IFRTP) and Terres Australes et Antarctiques Françaises (TAAF) provided logistical and financial support for this study. We are very grateful to Alain Caron at the University of Rimouski for the calculation of the sea floor surface. We also thank Graham Robertson and Barbara Wienecke of the Australian Antarctic Division for providing the dive recorders, as well as much useful advice and technical tips. We are indebted to Jean-Pierre Ouellet, Michel Gauthier-Clerc and David Grémillet, who read the draft and made useful comments to improve it. The Arctic \& Antarctic Research Center (Scripps Institution of Oceanography, La Jolla, CA, USA) provided the satellite imagery of the sea-ice. Our final thanks are to the winterers of the 46th and 47th French Expeditions at Dumont D'Urville for their help in the field work. 
Appendix 1. Dive depths and locations in relation to sea-floor topography, for the excluded emperor penguin that foraged over the continental shelf and in oceanic waters, in August and September 1997 (see 'Materials and methods')

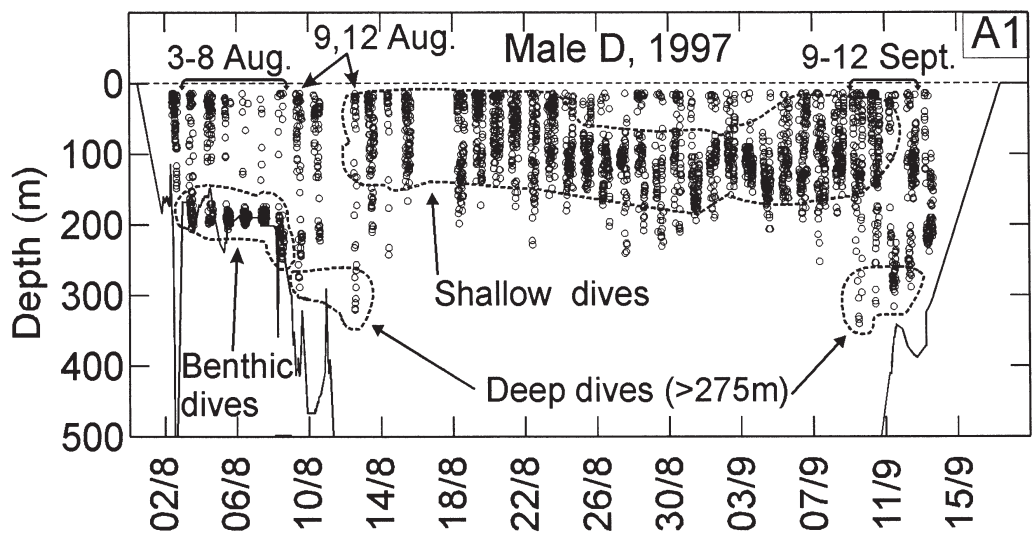

Foraging Days

Figs. A1 \& A2 refer to the same penguin (Male D), foraging in August and September 1997. Fig. A1 shows the relation between diving depths and sea floor depth during the trip, and Fig. A2 shows the foraging trip. Symbols are the same as in Figs. 1 \& 4 in the study, except for Fig. A2: for readability, the first half of the trip is shown as a continuous line, and the second half as a broken line. For the same reasons, the first days of foraging are stressed with white circles, and the last days with white crosses.

By comparing the 2 figures, it can be seen that after a day spent diving over a trench more than $500 \mathrm{~m}$ deep, Male D spent $5 \mathrm{~d}$ in benthic diving, from August 3 to 8, over the continental shelf and essentially in the same area as other males in 1997 (see Fig. 4b). On the next days (9 and 12 August) it performed a few deep dives under $275 \mathrm{~m}$ while leaving the continental shelf. It then dived mostly to shallow depths (0 to $150 \mathrm{~m}$ ) while foraging in very deep waters $(>2000 \mathrm{~m})$. When it was back on the shelf it performed deep dives again (9 to 12 September). By this time, fast ice had covered all shallow waters in this area (not shown) and Male D thus finished its foraging trip without diving (last straight segment of broken line in Fig. A2).

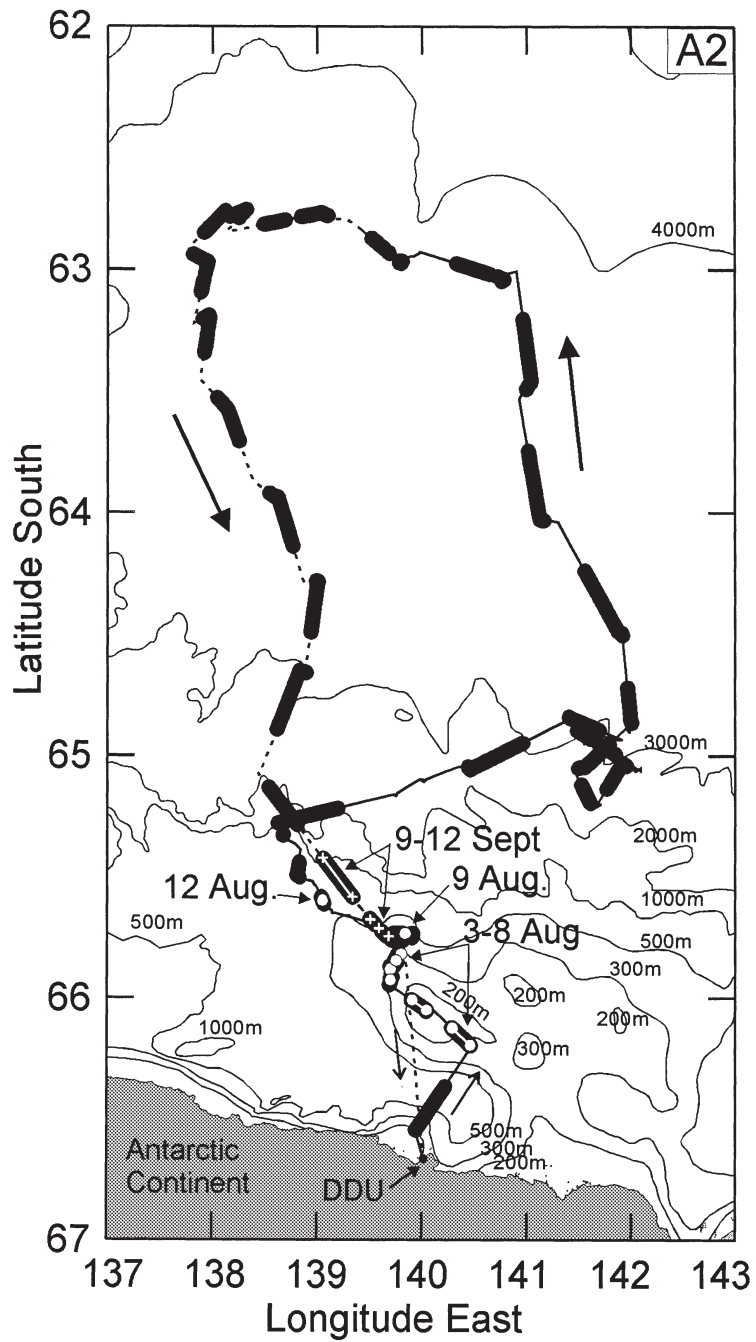




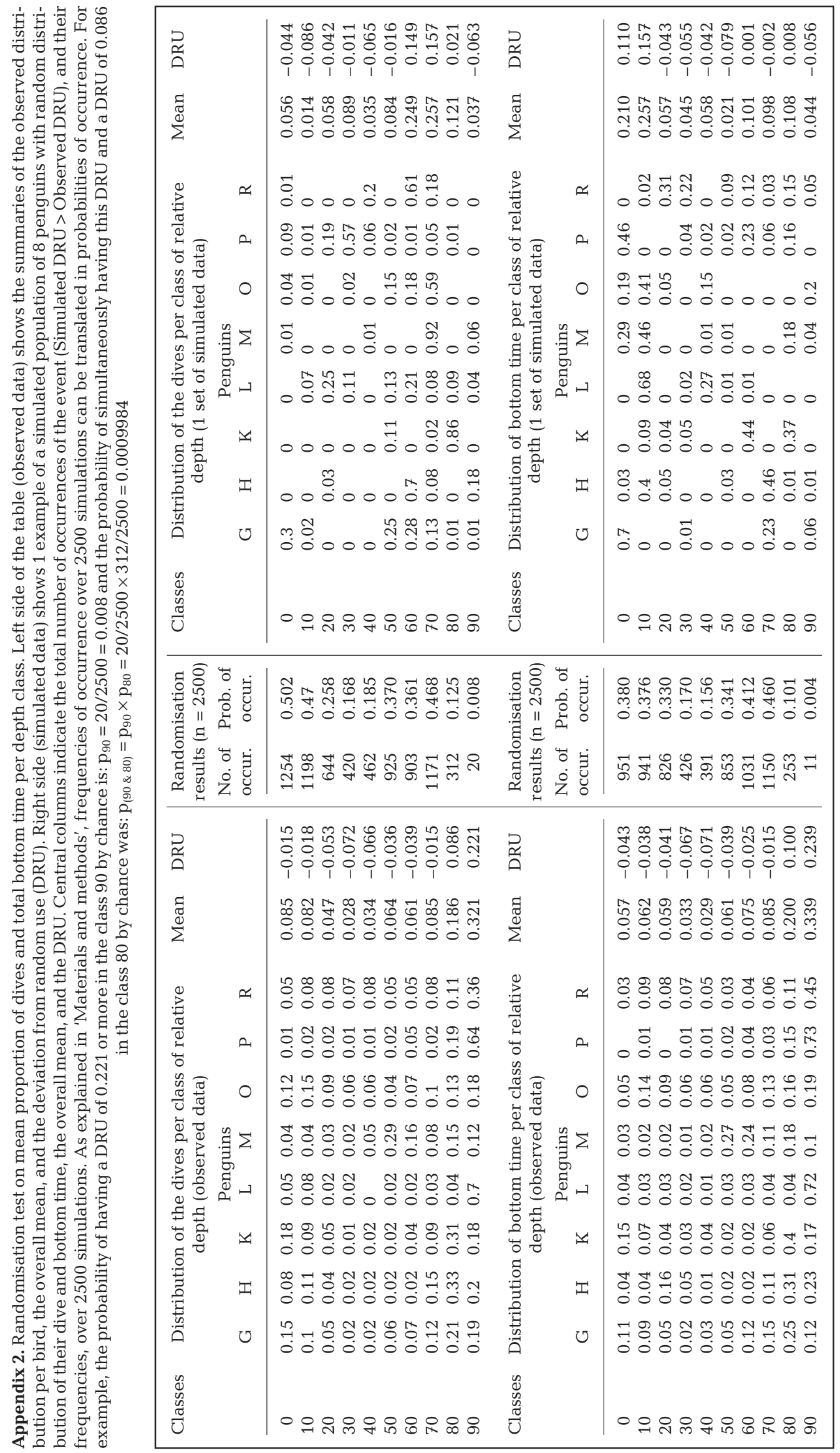




\section{LITERATURE CITED}

Aebischer NJ, Robertson PA, Kenward RE (1993) Compositional analysis of habitat use from animal radio-tracking data. Ecology 74(5):1313-1325

Ancel A, Kooyman GL, Ponganis PJ, Lignon J, Mestre X, Huin N, Thorson PH, Robisson P, Le Maho Y (1992) Foraging behavior of emperor penguins as a resource detector in winter and summer. Nature 360:336-339

Argos User Manual (1988) Guide to the Argos System. Argos CLS, Toulouse

Bannasch R, Wilson RP, Culik B (1994) Hydrodynamic aspects of design and attachment of a back-mounted device in penguins. J Exp Biol 194:83-96

Bost CA, Georges J, Guinet C, Cherel Y, Pütz K, Charassin JB, Handich Y, Zorn T, Lage J, Le Maho Y (1997) Foraging habitat and food intake of satellite-tracked king penguins during the summer at Crozet Archipelago. Mar Ecol Prog Ser 150:21-33

Boyd IL (1993) Selecting sampling frequency for measuring diving behavior. Mar Mammal Sci 9(4):424-430

Brey T, Clark A (1993) Population dynamics of marine benthic invertebrates in antarctic and subantarctic environments: are there unique adaptations? Antarct Sci 5(3):253-266

Brey T, Gerdes D (1997) Is Antarctic benthic biomass really higher than elsewhere? Antarct Sci 9(3):266-267

Costa DP (1991) Reproductive and foraging energetics of high latitude penguins, albatrosses and pinnipeds: implications for life history patterns. Am Zool 31:111-130

Hull CL, Hindell MA, Michael K (1997) Foraging zones of royal penguins during the breeding season, and their association with oceanographic features. Mar Ecol Prog Ser 153:217-228

Jouventin P, Stahl JC, Weimerskirch H, Mougin JL (1984) Seabirds of the French antarctic islands and Adélie Land, their status and conservation. In: Croxall JP, Evans PGH, Schreiber RW (eds) ICPB Seabird Conservation Symposium, 1982: Status and conservation of the world's seabirds, 609-625

Jouventin P, Barbraud C, Rubin M (1995) Adoption in the emperor penguin, Aptenodytes forsteri. Anim Behav 50: 1023-1029

Kirkwood R, Robertson G (1997a) The foraging ecology of female Emperor Penguins in winter. Ecol Monogr 67(2): $155-176$

Editorial responsibility: Otto Kinne (Editor), Oldendorf/Luhe, Germany
Kirkwood R, Robertson G (1997b) Seasonal change in the foraging ecology of emperor penguins on the Mawson Coast, Antarctica. Mar Ecol Prog Ser 156:205-223

Koch KH (1992) Antarctic fish and fisheries. Cambridge University Press, Cambridge

Kooyman GL, Kooyman TG (1995) Diving behavior of Emperor Penguins nurturing chicks at Coulman Island, Antarctica. Condor 97:536-549

Manly BFJ (1991) Randomization and Monte-Carlo methods in biology. Chapman \& Hall Inc, New York

National Geographic Data Center (1988) Data announcement 88-MGG-02, digital relief of the surface of the Earth. NOAA, National Geographic Data Center, Boulder, CO

Peters G (1997) A new device for monitoring gastric $\mathrm{pH}$ in free-ranging animals. Am J Physiol 273:748-753

Piatkowski U, Pütz K (1994) Squid diet of Emperor penguins (Aptenodytes forsteri) in the eastern Weddell Sea, Antarctica, during the austral summer. Antarct Sci Spec Issue 6(2):241-247

Pütz K, Bost CA (1994) Feeding behavior of free-ranging king penguins (Aptenodytes patagonicus). Ecology 75(2):489-497

Robertson G (1994) The foraging ecology of emperor penguins (Aptenodytes forsteri) at two Mawson Coast colonies, Antarctica. PhD thesis, University of Tasmania, Hobart

Robertson G, Williams R, Green K, Robertson L (1994) Diet composition of emperor penguin chicks Aptenodytes forsteri at two Mawson Coast colonies, Antarctica. Ibis 136: $19-31$

Rodary D, Wienecke BC, Bost CA (2000) Diving behaviour of Adélie penguins (Pygoscelis adeliae) at Dumont D'Urville, Antarctica: nocturnal patterns of diving and rapid adaptations to changes in sea-ice condition. Polar Biol 23:113-120

Wienecke BC, Robertson G (1997) Foraging space of emperor penguins Aptenodytes forsteri in Antarctic shelf water in winter. Mar Ecol Prog Ser 159:249-263

Wilson, RP, Ryan PG, Wilson MP (1989) Sharing food in the stomachs of seabirds between adult and chick-a case for delayed gastric emptying. Comp Biochem Physiol 94A: 461-466

Wilson RP, Clik BM, Bannasch R, Lage J (1994) Monitoring Antarctic variables using penguins. Mar Ecol Prog Ser 106:199-202

Wilson RP, Pütz K, Charassin JB, Lage J (1995) Artifacts arising from sampling interval in dive depth studies of marine endotherms. Polar Biol 15(8):575-581

Submitted: December 28, 1999; Accepted: April 2, 2000

Proofs received from author(s): October 30, 2000 